\title{
Aprendizagens na era digital: dentro e fora da escola
}

\author{
María Teresa Quiroz Velasco \\ Doutora em Sociologia. Diretora do Instituto de Investigação Científica da Universidade de \\ Lima. Professora e pesquisadora da Faculdade de Comunicação. Presidente do Tribunal de \\ Ética do Conselho da Imprensa Peruana. \\ E-mail: tquiroz@ulima.edu.pe
}

Resumo: Se a aprendizagem se estende para além dos muros da escola, é necessário reconhecer e integrar os conhecimentos que são transmitidos nas salas de aula, assim como as experiências, vivências e práticas do estudante fora delas. Com esse propósito, nos referiremos à relação entre comunicação e educação, sobre a qual, desde os anos 1980, inicia-se uma reflexão que se aprofunda e amplia na era digital. Sob este olhar, a educação não pode estar à margem das inovações sociais e tecnológicas porque os processos do aprender estão sendo afetados pelas relações que os mais jovens tecem com os meios de comunicação. Se a educação já ocorre em comunidades de aprendizagem pela exploração que se realiza na internet, por exemplo, é preciso entender e investigar sobre tudo aquilo que crianças e adolescentes conhecem, suas referências e opiniões sobre o mundo social e cotidiano.

Palavras-chave: educação escolar, comunicação, TIC, aprendizagens, redes sociais.
Abstract: If learning goes far beyond the walls of school, we need to recognize and integrate the knowledge conveyed through classrooms with the experiences schoolchildren have outside them. Upon this purpose, we shall refer to the relation of communication with education, about which there is an academic concern since the 1980's, increased and extended on the digital era. From that outlook, we cannot left education on the margins of social and technological innovation, since learning processes are being affected by the ties the younger generations keep with the media. If education is already ongoing in learning communities through the exploration done in the Internet, for example, it is really important to understand and to study about what do children and teenagers know, so as their references and opinions related with the social everyday world.

Keywords: school education, communication, ICT, learning, social networks.

\section{A EDUCAÇÃO E A COMUNICAÇÃO}

Para entender as relações entre educação e comunicação, convém definir a aprendizagem extraescolar. Se a aprendizagem formal, ou seja, a escolar é a ministrada por instituições formadoras que a credenciam, a não formal é aquela oferecida por organizações diversas e a informal é a que vem da família, dos amigos e dos meios de comunicação em geral. Sem dúvida, hoje há uma tendência a reforçar a 
1. COBO, Cristóbal e MORAVEC, John W. Aprendizaje invisible. Hacia una nueva ecología de la educación. Barcelona: Colleción Transmedia XXI, 2011, p. 92.

2. McBride et al. 1980; pp. $56-57$

3. QUIROZ, María Teresa. Todas las voces. Comunicación y educación en el Perú. Lima: Universidad de Lima, Facultad de Ciencias de la Comunicación, 1993, p. 17.

4. QUIROZ, 2004. complementariedade entre o formal, o não formal e o informal, na medida em que a educação se dá ao longo de toda a vida, na família e na escola, assim como nos espaços mais independentes e próprios da vida social e cotidiana. A esse respeito, Cobo e Moravec, ao se referirem à aprendizagem invisível, explicam: "a aprendizagem invisível ocorre quando o relevante não são os limites espaciais, mas sim as experiências de construção e reconstrução do conhecimento independentemente do objetivo, do entorno, do momento ou da frequência em que acontecem.

Pelas razões descritas, esse enfoque é muito mais próximo do princípio de "aprendizagem permanente" (também conhecido como "aprendizagem contínua" ou lifelong learning) do que o superexplorado e-learning ${ }^{1}$.

Se remontarmos ao ano de 1980, a UNESCO encomendou uma pesquisa à Comissão McBride que se materializou no livro Un solo mundo. Voces múltiples. Ali, se afirmou que a importância das relações entre o educativo e a comunicação se multiplicava pela extensão dos meios audiovisuais, e que o sistema educativo vinha perdendo o monopólio sobre a educação, fato que fazia com que a informação e a comunicação adquirissem um valor educativo de impacto na formação dos mais jovens ${ }^{2}$.

Ou seja, há mais de trinta anos os meios cresciam e seu consumo se estendia vertiginosamente, inundando a sensibilidade de crianças e adolescentes por meio das imagens e da música e, sobretudo, ocupando o tempo social e o imaginário dos mais jovens, que iam se tornando independentes dos discursos únicos e hegemônicos dos adultos. No entanto, durante um bom tempo, a resposta diante desses fatos se reduziu a condenar os meios, a assumir posturas moralistas de proteção aos menores e, por outro lado, a incorporar as tecnologias nas salas de aula como medida para modernizar a educação, mas sem ter em conta as mudanças que a comunicação produziu na subjetividade dos mais jovens. Assim o expressou Jesús Martín Barbero:

"o campo da comunicação/educação continua ainda hegemonizado por concepções instrumentais dos meios e por ideias ilustradas da educação. O que, na prática, se traduz no fato de que, em nossos países, continuem mantendo à margem, fora do sistema e das práticas educativas, as culturas que são geradas ou que se expressam nos meios de comunicação. Enquanto é cada dia maior o divórcio entre a cultura a partir da qual pensam e falam os professores e aquela outra a partir da qual veem e sentem os mais jovens, a escola continua tentando tapar sua crise de comunicação com rituais de modernização tecnológica e tentando reduzir seu conflito com a cultura audiovisual e informática a um discurso de lamentações morais"”.

Com o discurso da globalização, manifesta-se a ilusão de que os jovens recorrem à internet para adquirir conhecimentos e informação de todas as partes do mundo, o que contribuiria para melhorar a qualidade educativa. Pesquisas mostraram, porém, que a internet - no caso dos estudantes - era, sobretudo, um espaço para dar lugar ao sentir, às emoções e aos vínculos entre pares, e, em menor medida, para a aprendizagem ${ }^{4}$. Na pesquisa realizada no ano de 2008 nas cidades peruanas de Chiclayo, Iquitos e Cusco constatou-se que as escolas vinham se transformando pelo uso de tecnologias nas salas de aula, mas que os professores usavam os meios 
apenas como um recurso tecnológico, sem integrá-los a sua proposta pedagógica. Ou seja, faziam "mais do mesmo", sem levar em consideração a participação e a interação dos alunos nem promover o trabalho colaborativo por meio da inovação e da investigação. Por outro lado, os adolescentes consultados expressaram seu entusiasmo com as imagens que os ajudavam a conhecer e imaginar, esclarecendo que aprendiam por meio da televisão, sobretudo, a televisão a cabo. Identificou-se o uso da internet crescente e invasivo fora da escola e a satisfação dos estudantes com o acesso à rede, especialmente com a possibilidade de compartilhar estados de ânimo a distância. Era notório que preferiam a simultaneidade e a rapidez da internet à linearidade visual da televisão, particularmente à de sinal aberto ${ }^{5}$. Em pesquisa publicada no ano de 2013, constata-se que a vida fora da escola e os vínculos que mantêm nas redes sociais são fundamentais para a socialização e a construção de suas próprias identidades. Os adolescentes declaram que enquanto fazem as tarefas, conversam no chat ou se divertem, entram no Facebook, e que gostam de aprender enquanto se entretêm. É de se ressaltar que a iniciativa de usar a internet tem mais a ver com os interesses particulares dos adolescentes do que com uma proposta pedagógica da escola, mesmo que isto varie segundo se trate de escolas públicas ou privadas ${ }^{6}$.

É possível afirmar que, na atualidade, o estudante vincula a comunicação e a educação em suas práticas cotidianas, porque seus conhecimentos e sua visão de mundo não dependem exclusivamente dos conteúdos escolares organizados para tal fim. O estudante tende a ser mais autônomo em sua busca por informação, tem muito contato com os meios de comunicação e com outras fontes informativas, e ensaia suas próprias interpretações.

\section{UTILIZAÇÃO FORMAL E INFORMAL DAS TIC}

Hoje em dia, discute-se intensamente, tanto nas instâncias de governo e supranacionais quanto entre professores e pais, sobre a qualidade da educação e o efeito da incorporação de tecnologias nas salas de aula. Nas avaliações realizadas, expressam-se certa reserva sobre os efeitos e as mudanças na educação produzidos pela incorporação de computadores e internet. Constata-se que, mesmo com o investimento em tecnologias, prevalecem as práticas educativas normatizadas e centradas na transmissão de conhecimentos. Apesar disso, é preciso notar que, se, por um lado as políticas educativas inicialmente se limitaram a dotar os centros educativos de infraestrutura tecnológica, com o passar do tempo, o emprego dessas ferramentas vem sendo associado à melhora da educação básica, assim como à produção de conhecimentos, a comunicação e a participação na sociedade ${ }^{7}$.

As pesquisas e os estudos coincidem em assinalar que não se trata de um problema de tecnologia, mas sim de pensamento e atitude que permitam empreender uma escola mais flexível, personalizada e ubíqua. Ou seja, um paradigma educativo que se funda na comunidade de aprendizes, que deixa
5. CORTINA, A. Cidadãos do mundo: para uma teoria da cidadania. São Paulo: Loyola, p. 30, 2005.

6. QUIROZ, María Teresa. Sin muros. Aprendizajes en la era digital. Lima: Fondo Editorial Universidad de Lima, 2013.

7. STEINBERG, Cora. Televisión, Internet y educación básica. [Televisão, internet e educação básica]. Buenos Aires: UNICEF, 2013. 
8. STEINBERG, Cora. Televisión, Internet y educación básica. Buenos Aires: UNICEF, 2013, p. 32.

9. UNESCO. Enfoques estratégicos sobre las TICS en educación en América Latina y $\mathrm{El} \mathrm{Ca}$ ribe". Santiago de Chile: UNESCO, 2013, p. 36 10. JENKINS, 2013.

11. STEINBERG, Cora. Televisión, Internet y educación básica. Buenos Aires: UNICEF, 2013, p. 97.

12. PISCITELLI, Alejandro. "Video TV, ergo sum. Cuando la cultura audiovisual también sirve para pensar (se) y hacer pensar". In: Orozco Guillermo, TVMORFOSIS: la televisión abierta hacia una sociedad de redes. México: Productora de Contenidos Culturales, 2012

13. BARICCO, Alessandro. Los bárbaros. Ensayo sobre la mutación. Barcelona: Anagrama, 2008.

14. CARR, Nicholas Superficiales.¿Qué está haciendo INTERNET con nuestras mentes? Taurus: Buenos Aires, 2011.

15. PISCITELLI, Alejandro. Video TV, ergo sum. Cuando la cultura audiovisual también sirve para pensar (se) y hacer pensar. In: Orozco Guillermo. TVMORFOSIS: la televisión abierta hacia una sociedad de redes. México: Productora de Contenidos Culturales, 2012, p. 100.

16. Idem, p. 102

17. MORDUCHOWICZ, Roxana. Los jóvenes y las pantallas: nuevas formas de sociabilidad. In: Morduchowicz, Roxana (coordenadora). Los jóvenes y las pantallas. Nuevas formas de sociabilidad. [Os jovens e as telas. Novas formas de sociabilidade]. Barcelona: Gedisa, 2008, p. 19. de lado a ideia do conhecimento único transmitido pelo professor como dono do saber, que se refere a "uma comunidade de pessoas que busca, seleciona, constrói e comunica conhecimento colaborativamente num tipo de experiência que se conecta diretamente com o conceito de comunidades de aprendizagem" $\mathrm{O}$ professor se converte num ator fundamental como promotor de redes sociais de conhecimento, da autoaprendizagem que respeita os interesses de crianças e adolescentes, "de tecnologias que facilitem a ubiquidade das experiências educativas mediante plataformas disponíveis e acessíveis a partir de diferentes dispositivos, lugares e momentos"9.

Por isso, parece cada vez mais urgente entrelaçar o mundo da comunicação - do qual os mais jovens são parte fundamental - com o mundo da educação, e estabelecer a relação entre televisão, internet e educação. Em todos os setores da comunicação, debate-se sobre o lugar da audiência e como esta deixa de ser passiva e se transforma em grupos mais ativos. Assim, não interessa o que os meios fazem com as pessoas, mas sim o que as pessoas fazem com os meios ${ }^{10}$. Nas próprias salas de aula, se sobrepõem estas tecnologias e "convivem lousas, slides, cadernos, projetores, telas, TV e, hoje, computadores"11. Nesse sentido, é um equívoco opor os meios consumidos fora e dentro da sala de aula - os primeiros com finalidades de entretenimento e os segundos, de educação -, devido a que todos se encontram integrados nas práticas sociais e educativas.

Diante das aprendizagens tradicionais centradas no esforço, na concentração e na atenção, competem novas aprendizagens, invisíveis e colaterais, relacionadas com operações complexas e múltiplas que exercitam habilidades lógicas para resolver situações em novos entornos e com um pensamento sistêmico ${ }^{12}$. Apesar de posturas muito críticas como as já conhecidas de Sartori e outros como Alessandro Barrico ${ }^{13}$ e Nicholas Carr ${ }^{14}$, Alejandro Piscitelli, citando a Johnson ${ }^{15}$, acredita que a TV sim serve para pensar, e que, muito melhor do que continuar identificando as mensagens audiovisuais como produto de professores desviados ou como promotores onipotentes da incultura juvenil, seria entendê-los como uma forma de treinamento em cognição diversificada e complexa ${ }^{16}$. Novas narrativas presentes nas séries e videogames, por exemplo, supõem que as capacidades cognitivas não estão associadas somente à leitura, e que as crianças têm interesses e perspectivas que devem ser consideradas. Antes, os adultos podiam controlar o entorno cultural e simbólico de crianças e adolescentes; hoje em dia, a leitura hipertextual e não linear que eles praticam e que a internet possibilita, supõe novas habilidades. Passou-se do zapping diante da tela da televisão ao zapping na vida cotidiana. Enquanto na sala de aula se privilegia o linear, as crianças se movem num universo regido por parâmetros diferentes daqueles que a cultura escolar legitima, porque vivem numa cultura do simultâneo ${ }^{17}$.

Definitivamente, é necessário recuperar o que acontece fora das salas de aula, porque a escola não é feita apenas de conteúdos transmitidos pelo professor. Crianças e adolescentes contribuem com seu próprio mundo, real e subjetivo, que é necessário reconhecer e valorizar. Infelizmente, a escola como instituição, e autoridades e professores levam uma pesada carga centrada na 
escrita e na palavra. Desconhecem-se "as culturas que começavam a surgir e conviver com ela fora da sala de aula: primeiro, a que foi proposta pelo cinema; em seguida, a televisão e, mais recentemente, as novas tecnologias"18. Isto pode explicar porque o livro se associa à razão, à argumentação e ao pensamento, enquanto o campo das imagens ficou desvalorizado pela escola e pelos adultos ${ }^{19}$. Os muros da escola desvaneceram, apesar dela mesma, porque o saber não está circunscrito a estes limites, e também porque desvaneceram os da idade, estendendo-se a educação ao longo da vida. Cassany afirma que, gostemos ou não, o letramento está migrando para formatos eletrônicos a um ritmo rápido e irreversível. A comunicação eletrônica - com computador, tela e internet - está substituindo a escrita com papel e lápis - com livros, cartas e correio postal ${ }^{20}$. Assim assinala José Joaquín Brunner em sua intervenção no Seminário da CEPAL, insistindo em que é necessário reinventar integralmente a educação como parte de uma nova cultura para que os mais jovens olhem para seu próprio futuro considerando o que significa

"viver num entorno em que já não há escassez, mas sim superabundância de informação, em que a aprendizagem é cada vez mais heterônoma, em que o mundo escolar perde o monopólio cognitivo, em que os profissionais da transmissão seriada veem suas competências e habilidades prontamente desvalorizadas"21.

\section{SOBRE AS TIC NAS ESCOLAS PERUANAS}

Nesta linha, permito-me mencionar duas histórias que nos falam dos esforços criativos para integrar tecnologias, dentro e fora da escola. A primeira é a do professor Carlos Tinoco e suas alunas, que, pelo terceiro ano consecutivo, sobem ao pico nevado Copa em Huaraz (cidade do interior do Peru) com seus laptops XO (entregues pelo programa OLPC "Um computador por criança”) e registram o avanço do desgelo, tirando fotos e gravando as mudanças do pico. Depois de constatar que o pico perde cerca de 12 metros de gelo por ano, compartilham suas imagens, realizam trabalhos em grupo com suas fotos e vídeos e, posteriormente, mostram à comunidade as mudanças da montanha (El Peruano, 2013). A segunda é a do professor Carlos Montoya do Colégio San Juan em San Juan de Miraflores (distrito da cidade de Lima). Neste caso, a lousa de fundo verde e o giz, substituídos por quadro branco e pincel, foram convertidos numa lousa digital interativa, incorporando o uso de vídeos do YouTube e recuperando uma série de referências além dos conteúdos formais estabelecidos.

O extraordinário destas duas iniciativas - das quais seguramente há dezenas desconhecidas e não valorizadas como precedentes na melhora da educação encontra-se no uso da tecnologia para vincular a vida cotidiana e o conhecimento de mundo ao ensino e à aprendizagem na sala de aula. Pudemos verificar que as lacunas são muitas e profundas porque afetam o futuro educativo e laboral dos educandos. As iniciativas mencionadas lançam luz sobre as possibilidades
18. Idem, p. 19

19. Idem.

20. CASSANY, Daniel. Tras las líneas. Sobre la lectura contemporánea. [Por trás das linhas. Sobre a leitura contemporânea]. Barcelona: Anagrama, 2006, p. 171.

21. PISCITELLI, Alejandro. Video TV, ergo sum. Cuando la cultura audiovisual también sirve para pensar (se) y hacer pensar. In: Orozco Guillermo. TVMORFOSIS: la televisión abierta hacia una sociedad de redes. México: Productora de Contenidos Culturales, 2012.

22. PISCITELLI, Alejandro. Video TV, ergo sum. Cuando la cultura audiovisual también sirve para pensar (se) y hacer pensar. In: Orozco Guillermo. TVMORFOSIS: la televisión abierta hacia una sociedad de redes. México: Productora de Contenidos Culturales, 2012. 
23. СOBO, Cristóbal e MORAVEC, John W. Aprendizaje invisible. Hacia una nueva ecología de la educación. Barcelona: Colleción Transmedia XXI, 2011.

24. MINISTÉRIO DA EDUCAÇÃO. Apresentação em café da manhã de trabalho: Enfoques y perspectivas de las TIC para la educación, 2013.

25. SILVA, Marco. Educación interactiva. Enseñanza y aprendizaje presencial y on-line. [Educação interativa. Ensino e aprendizagem presencial e on-line]. Barcelona: Gedisa, 2005, p. 102. de enfrentar o divórcio entre cultura e educação, dada a separação entre aprendizagem e escolarização ${ }^{22}$. Nessa mesma linha, Cristóbal Cobo e John Moravec comparam as tecnologias e a aprendizagem na escola e em casa e assinalam que "as competências adquiridas nos entornos informais são invisíveis. Há mais impactos, produtos do uso das tecnologias em casa do que na escola, já que na sala de aula estes dispositivos digitais (ainda) não geram um claro efeito no que diz respeito ao avanço educativo"23.

O próprio Ministério da Educação do Peru estabeleceu uma agenda de futuro que contempla a integração entre o que acontece dentro e fora das salas de aula ${ }^{24}$ e que propõe o seguinte:

- Utilizar os videogames no processo de ensino/aprendizagem, dados seus efeitos sobre os processos cognitivos;

- Pesquisar sobre as tecnologias do ponto de vista dos alunos;

- Desenvolver a alfabetização digital entre docentes e pais;

- Definir as competências e certificações TIC para os professores;

- Utilizar os celulares;

- Propor novas formas de avaliação acadêmica com/de TIC.

Esta agenda parecer muito importante porque expressa uma visão que recupera o educando em suas diferentes práticas educativas e culturais e procura responder à situação atual, tendo em conta o fora e o dentro da escola. Ademais, estas propostas correspondem a um pensamento que supõe que as aprendizagens não são apenas as formais, plasmadas nos planos de ensino, e que as respostas não se encontram no que se aprende, mas sim em como se aprende. $\mathrm{O}$ mundo atual requer sujeitos que saibam como fazer as coisas (know how) mais do que pessoas que unicamente repetem procedimentos. Em outras palavras, pessoas que reconheçam qual é a informação relevante, por que e como conectá-la com outras fontes. A ênfase desta perspectiva está no que fazer com o conhecimento ${ }^{-25}$.

\section{CONCLUSÕES}

É clara e crescente a tendência que indica que as aprendizagens não se reduzem à escola, à leitura de textos e à aquisição de conteúdos. Aprende-se muitas vezes fora da escola, com maior liberdade e com mais tempo para indagar, ainda que sem objetivos pedagógicos definidos.

Se o problema não é tecnológico nem exclusivamente educativo, mas também de comunicação, é preciso propor alternativas que integrem as tecnologias digitais aos processos de aprendizagem dentro e fora da escola. Isto requer debates entre autoridades políticas e educativas, assim como com os pais de família e os próprios estudantes para propor políticas.

Nas plataformas digitais se multiplicam dia a dia as formas de inter-relação dos jovens, e a educação e as aprendizagens não podem ficar alheios a estes 
espaços. Urge a necessidade de transitar de um modelo pedagógico que se ancora na transmissão de conhecimentos a outro que se organiza e fundamenta na interatividade. Caminhar de um modelo linear e centralizado para outro, descentralizado e plural, seguindo as exigências comunicacionais e cognitivas que nos sugerem os jovens. Manter seu interesse e sua atenção é complexo e difícil, trata-se de um grupo geracional para o qual os modelos lineares e argumentativos tradicionais não bastam para comunicar um sentido. Os mais jovens se desenvolvem melhor que seus professores e adultos na variedade de conexões, relacionando a informação com a comunicação, produzindo conteúdos e compartilhando-os.

Por este motivo, as decisões políticas no setor educativo e as políticas de gestão no interior das escolas são francamente insuficientes, porque não alcançam o sentido das mudanças relacionadas à função comunicadora do educar, limitam-se, ainda e em geral, a investir em máquinas e tecnologias informáticas. O problema não pode se reduzir ao treinamento dos professores para o manejo de computadores ou a navegação na internet. Trata-se de trabalhar e prepara os docentes para que compreendam o sentido da formação de seus estudantes como futuros cidadãos, como sujeitos autônomos com capacidades para discernir, e muito criativos. $\mathrm{O}$ brasileiro Marco Silva explica que a interatividade é um conceito de comunicação, e não de informática, e que "o professor deve ser um comunicador, pode se sintonizar com a nova cultura comunicacional na sala de aula" ${ }^{26}$.

Por estes motivos, somo-me àqueles que sustentam que falta desenvolver, na educação, pesquisas sobre os efeitos da TV e da internet nos processos de ensino e aprendizagem, tanto no desenvolvimento cognitivo quanto na qualidade das aprendizagens alcançadas. Porém, ademais, é preciso conhecer os valores e percepções que têm os docentes, alunos e a família ${ }^{27}$. Os resultados destas pesquisas nos permitirão enfrentar as diferenças e propor as medidas mais acertadas ${ }^{28}$.

Os muros institucionais já não comportam todo o saber e o valor do que acontece do lado de fora que parece fundamental nas aprendizagens e no desempenho social e cidadão dos estudantes.

\section{REFERÊNCIAS}

BARICCO, Alessandro. Los bárbaros. Ensayo sobre la mutación. [Os bárbaros. Ensaio sobre a mutação]. Barcelona: Anagrama, 2008.

CARR, Nicholas. Superficiales. ¿Qué está haciendo INTERNET con nuestras mentes? [Superficiais. O que a internet está fazendo com nossas mentes?] Taurus: Buenos Aires, 2011.

CASSANY, Daniel. Tras las líneas. Sobre la lectura contemporánea. [Por trás das linhas. Sobre a leitura contemporânea]. Barcelona: Anagrama, 2006.

COBO, Cristóbal e MORAVEC, John W. Aprendizaje invisible. Hacia una nueva ecología de la educación. [Aprendizagem invisível. Por uma nova ecologia da educação]. Barcelona: Colleción Transmedia XXI, 2011.
26. SILVA, Marco. Educación interactiva. Enseñanza y aprendizaje presencial y on-line. [Educação interativa. Ensino e aprendizagem presencial e on-line]. Barcelona: Gedisa, 2005, p. 16.

27. STEINBERG, Cora. Televisión, Internet y educación básica. [Televisão, internet e educação básica]. Buenos Aires: UNICEF, 2013.

28. Idem; pp. 93-95. 
comunicação \& educação • Ano XX • número 1 • jan/jun 2015

MINISTÉRIO DA EDUCAÇÃO. Apresentação em café da manhã de trabalho: Enfoques y perspectivas de las TIC para la educación [Enfoques e perspectivas das TIC para a educação], 2013.

MORDUCHOWICZ, Roxana. Los jóvenes y las pantallas: nuevas formas de sociabilidad. In: Morduchowicz, Roxana (coordenadora). Los jóvenes y las pantallas. Nuevas formas de sociabilidad. [Os jovens e as telas. Novas formas de sociabilidade]. Barcelona: Gedisa, 2008.

QUIROZ, María Teresa. Sin muros. Aprendizajes en la era digital. [Sem muros. Aprendizagens na era digital]. Lima: Fondo Editorial Universidad de Lima, 2013.

QUIROZ VELASCO, María Teresa. Tecnologías digitales: para la educación y la comunicación. In: Tecnologias digitais: reflexões e perspectivas. São Paulo: Escola de Comunicações e Artes, 2012.

QUIROZ VELASCO, María Teresa. La edad de la pantalla. Tecnologías interactivas y jóvenes peruanos. [A idade da tela. Tecnologias interativas e jovens peruanos]. Lima: Fondo Editorial Universidad de Lima, 2008.

QUIROZ, María Teresa. Todas las voces. Comunicación y educación en el Perú. [Todas as vozes. Comunicação e educação no Peru]. Lima: Universidad de Lima, Facultad de Ciencias de la Comunicación, 1993.

PISCITELLI, Alejandro. Video TV, ergo sum. Cuando la cultura audiovisual también sirve

para pensar (se) y hacer pensar. In: Orozco Guillermo. TVMORFOSIS: la televisión abierta hacia una sociedad de redes. [TVMORFOSE: a televisão aberta a uma sociedade de redes].México: Productora de Contenidos Culturales, 2012.

SILVA, Marco. Educación interactiva. Enseñanza y aprendizaje presencial y on-line. [Educação interativa. Ensino e aprendizagem presencial e on-line]. Barcelona: Gedisa, 2005.

STEINBERG, Cora. Televisión, Internet y educación básica. [Televisão, internet e educação básica]. Buenos Aires: UNICEF, 2013. Disponível em: <http:/ /www. unicef.org/argentina/spanish/educacion_Television_Internet_educacion_ basica.pdf>. Acesso em: 15 out. 2013.

UNESCO. Enfoques estratégicos sobre las TICS en educación en América Latina y El Caribe”. [Enfoque estratégicossobre as TIC's na educação na América Latina e no Caribe]. Santiago de Chile: UNESCO, 2013. 